\title{
Response of 4H-SiC Detectors to Ionizing Particles
}

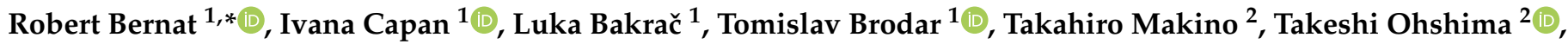 \\ Željko Pastuović ${ }^{3}$ and Adam Sarbutt ${ }^{3}$ \\ 1 Ruđer Bošković Institute, Bijenička cesta 54, 10000 Zagreb, Croatia; capan@irb.hr (I.C.); \\ luka.bakri@gmail.com (L.B.); tbrodar@irb.hr (T.B.) \\ 2 National Institutes for Quantum and Radiological Science and Technology, 1233 Watanuki, Takasaki 370-1292, \\ Japan; makino.takahiro@qst.go.jp (T.M.); ohshima.takeshi@qst.go.jp (T.O.) \\ 3 Australian Nuclear Science and Technology Organisation, 1 New Illawarra Rd., Lucas Heights, NSW 2234, \\ Australia; zkp@ansto.gov.au (Ž.P); adam.sarbutt@gmail.com (A.S.) \\ * Correspondence: rbernat@irb.hr
}

check for updates

Citation: Bernat, R.; Capan, I.; Bakrač, L.; Brodar, T.; Makino, T.; Ohshima, T.; Pastuović, Ž.; Sarbutt, A. Response of $4 \mathrm{H}-\mathrm{SiC}$ Detectors to Ionizing Particles. Crystals 2021, 11, 10. https:// dx.doi.org/10.3390/ cryst11010010

Received: 4 December 2020

Accepted: 22 December 2020

Published: 24 December 2020

Publisher's Note: MDPI stays neutral with regard to jurisdictional claims in published maps and institutional affiliations.

Copyright: (c) 2020 by the authors. Licensee MDPI, Basel, Switzerland. This article is an open access article distributed under the terms and conditions of the Creative Commons Attribution (CC BY) license (https: / / creativecommons.org/ licenses/by/4.0/).

\begin{abstract}
We report the response of newly designed 4H-SiC Schottky barrier diode (SBD) detector prototype to alpha and gamma radiation. We studied detectors of three different active area sizes $(1 \times$ $1,2 \times 2$ and $3 \times 3 \mathrm{~mm}^{2}$ ), while all detectors had the same $4 \mathrm{H}$-SiC epi-layer thickness of approximately $\mu \mathrm{m}$, sufficient to stop alpha particles up to $6.8 \mathrm{MeV}$, which have been used in this study. The detector response to the various alpha emitters in the $3.27 \mathrm{MeV}$ to $8.79 \mathrm{MeV}$ energy range clearly demonstrates the excellent linear response to alpha emissions of the detectors with the increasing active area. The detector response in gamma radiation field of Co-60 and Cs-137 sources showed a linear response to air kerma and to different air kerma rates as well, up to $4.49 \mathrm{~Gy} / \mathrm{h}$. The detector response is not in saturation for the dose rates lower than $15.3 \mathrm{mGy} / \mathrm{min}$ and that its measuring range for gamma radiation with energies of $662 \mathrm{keV}, 1.17 \mathrm{MeV}$ and $1.33 \mathrm{MeV}$ is from $0.5 \mathrm{mGy} / \mathrm{h}-917 \mathrm{mGy} / \mathrm{h}$. No changes to electrical properties of pristine and tested $4 \mathrm{H}-\mathrm{SiC}$ SBD detectors, supported by a negligible change in carbon vacancy defect density and no creation of other deep levels, demonstrates the radiation hardness of these $4 \mathrm{H}-\mathrm{SiC}$ detectors.
\end{abstract}

Keywords: silicon carbide; radiation detector; radiation response; alpha particles; gamma radiation

\section{Introduction}

Silicon carbide, a wide band-gap semiconductor with exceptional thermal and mechanical stability [1,2], is now one of the most investigated materials for radiation particle detection. It has a very low leakage current, of an order of $\mathrm{nA}$, which has a high influence in radiation detection applications [3]. The high threshold displacement energy of the material leads to a high level of radiation hardness compared with other common semiconductor detector materials [4,5], whereas the strong covalent bonds between atoms also makes the materials mechanically strong. Due to its radiation hardness, fast switching-capability, insensitivity to visible light, and biocompatibility, $\mathrm{SiC}$ is used for many other applications such as radiation hard electronics, high temperature coatings, biomedical sensors, UV-light sensors and others [6-9]. The radiation detectors based on $4 \mathrm{H}$-polytype $\mathrm{SiC}$ epitaxial layers are mostly used as a charged particle [10,11] and neutron detectors [12]. In the past decades, the research on response of the $4 \mathrm{H}-\mathrm{SiC}$ based detectors to charged particles and directly or indirectly, via neutron converters, to neutrons has been in focus. On the other hand, response of the $4 \mathrm{H}-\mathrm{SiC}$-based detectors to gamma radiation has not been extensively studied. Several authors reported on gamma and beta particle response of the SiC-based detectors, and were able to directly detect and distinguish different radiation types [10,13-15].

Our previously published results cover neutron detection testing activities performed at the Jožef Stefan Institute (JSI) TRIGA reactor in the framework of the E-SiCure project [12,16] with $4 \mathrm{H}-\mathrm{SiC}$ SBD's with sizes of $1 \mathrm{~mm} \times 1 \mathrm{~mm} \times 25 \mu \mathrm{m} / 69 \mu \mathrm{m}$ and $170 \mu \mathrm{m}$ and using ${ }^{6} \mathrm{LiF}$ and ${ }^{10} \mathrm{~B}_{4} \mathrm{C}$ as converter films. In order to optimize neutron detection sensitivity of 
$4 \mathrm{H}-\mathrm{SiC}$ detectors, it is necessary to understand the behavior of bare detectors in various radiation fields, other than the neutron one. Keeping in mind that the detection principle lie in the detection of charged particles, the response of the detector to alpha particles is of a particular importance. The best energy-resolution of $0.29 \%$ for $5486 \mathrm{keV}$ alpha particles to date, has been reported by Mandal et al. [17] with 100\% charge collection efficiency (CCE). The energy resolution was found to be dependent on the defect type and concentrations within the $4 \mathrm{H}-\mathrm{SiC}$ epitaxial layers and on the noise of the detector and associated electronic modules of the detector system [11,17-19].

In this paper, we present comprehensive electrical characterization and radiation response of $4 \mathrm{H}-\mathrm{SiC}$ detectors with different active surface areas $\left(1 \mathrm{~mm}^{2}, 4 \mathrm{~mm}^{2}\right.$ and $9 \mathrm{~mm}^{2}$ ) to different radiation fields. All $4 \mathrm{H}-\mathrm{SiC}$ detectors have the same thickness of the epitaxial layers, which is $25 \mu \mathrm{m}$. We have used a wide range of alpha particles which covered energies up to $8.79 \mathrm{MeV}$, which was high enough to establish a connection between thickness of the epitaxial layer and particle energy. Testing the response of $4 \mathrm{H}-\mathrm{SiC}$ detectors to gamma radiation was performed using Co-60 and Cs-137 calibration sources.

\section{Materials and Methods}

A typical SiC-based detector has the structure of an SBD, shown in Figure 1. Due to band alignment, a volume of depleted carriers is created at the semiconductor side of the junction, making the device very sensitive to the presence of electron-hole pairs generated upon illumination with above band-gap UV light or upon exposure to ionizing radiation. Since neutrons do not interact with valence electrons [20], their presence is deduced from the detection of ionizing neutron reaction products, like gamma rays, alpha particles, tritons, and larger ions. The SBD is operated under reverse bias, which increases the potential drop across the semiconductor and increases the depletion width. To limit the required operation voltage, the doping level of the substrate is usually two orders of magnitude higher than that of the epi-layer. Detailed specifications of $4 \mathrm{H}-\mathrm{SiC}$ detectors have been reported elsewhere by several authors $[18,21,22]$.

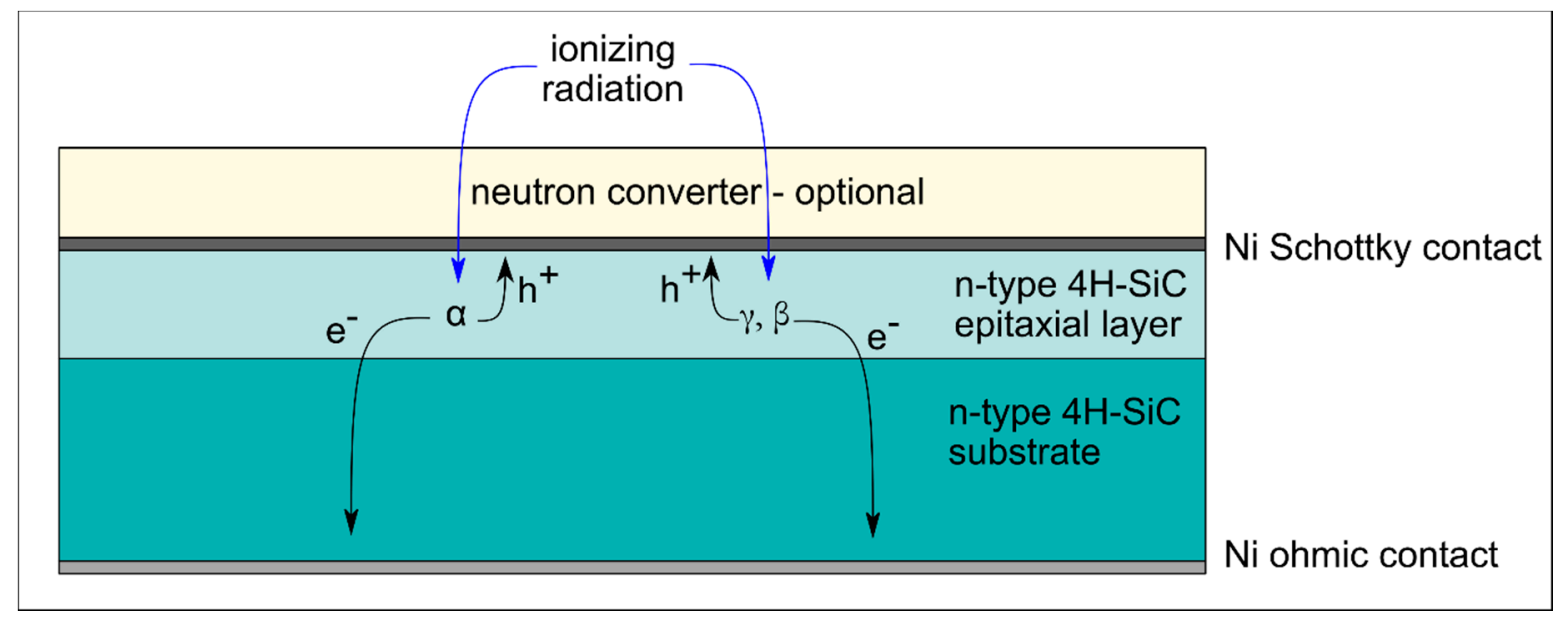

Figure 1. Design of a $4 \mathrm{H}-\mathrm{SiC}$ SBD suitable for detection of ionizing radiation. A converter layer covering the front contact is optional and can substantially enhance the detection sensitivity to thermal neutrons.

4H-SiC SBDs were manufactured at the National Institutes for Quantum and Radiological Science and Technology in Japan (QST).

n-type SBDs were produced on nitrogen-doped (up to $4.5 \times 10^{14} \mathrm{~cm}^{-3}$ ) $4 \mathrm{H}-\mathrm{SiC}$ epitaxial layers, approximately $25 \mu \mathrm{m}$ thick [23]. The epitaxial layer was grown on the silicon face ( $8^{\circ}$ off) of $350 \mu$ m-thick silicon carbide substrate without the buffer layer. The Schottky barrier was formed by thermal evaporation of nickel through a metal mask with patterned square apertures of $1 \times 1 \mathrm{~mm}^{2}, 2 \times 2 \mathrm{~mm}^{2}$, and $3 \times 3 \mathrm{~mm}^{2}$, while Ohmic contacts 
were formed on the backside of the silicon carbide substrate by nickel sintering at $950{ }^{\circ} \mathrm{C}$ in the Ar atmosphere.

The SBDs were mounted and wire-bonded onto chip carriers with two strip copper contacts. A coaxial cable (connected to the copper contacts on the chip carrier) was used to apply a reverse bias voltage to the SBD and to convey the signal to the data acquisition system. In order to isolate the detector components under high voltage, the chip carriers bearing the SiC SBDs were mounted into 3D printed plastic enclosures (Figure 2).

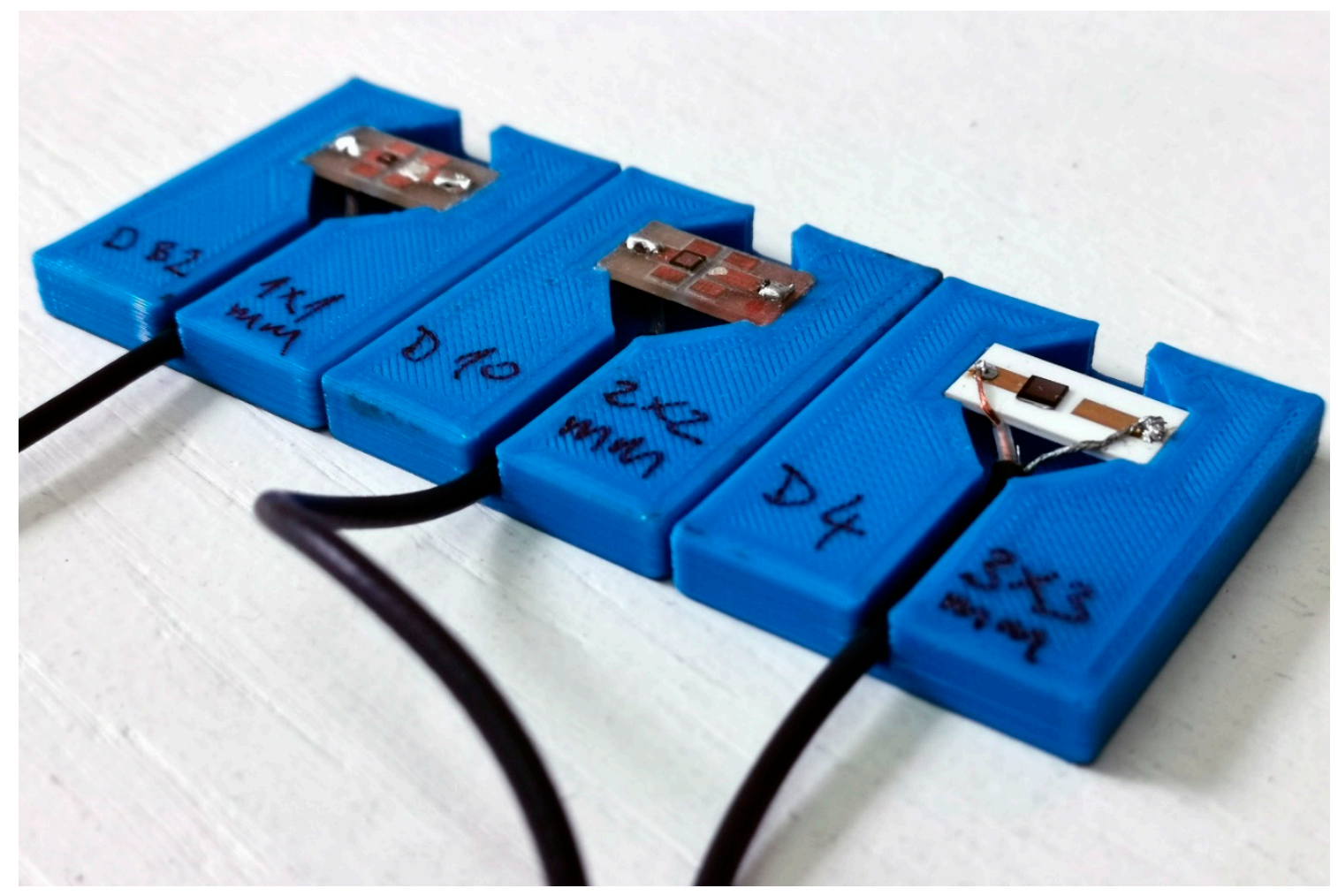

Figure 2. Three SBDs with different active volume were mounted into plastic enclosures.

The quality of the fabricated 4H-SiC SBDs was assessed by current-voltage (I-V) and capacitance-voltage $(\mathrm{C}-\mathrm{V})$ measurements. Measurements were carried out using a Keithley 6487 Picoammeter/Voltage Source and a Keithley 4200 Semiconductor characterization system (Keithley Instruments, Cleveland, OH, USA). Measurements were carried out in vacuum, at room temperature. Electrically active defects were characterized by deep level transient spectroscopy (DLTS) [24,25]. DLTS measurements were carried out in the temperature range from 150 to $400 \mathrm{~K}$. The $4 \mathrm{H}-\mathrm{SiC}$ detectors were cooled down from room temperature without an applied bias before DLTS measurements. The temperature ramp rate was $2 \mathrm{~K} / \mathrm{min}$. Capacitance transients were measured using a Boonton (Boonton Electronics, Parsippany, NJ, USA) 7200 capacitance meter using a $30 \mathrm{mV}, 1 \mathrm{MHz}$ sinusoidal signal.

We have made extensive studies of the $4 \mathrm{H}-\mathrm{SiC}$ detectors response to the alpha particles, and we have used several alpha sources for testing and calibrations: mixed electroplated alpha source of Pu-239, Am-241 and Cm-244 (A = 3.7 kBq), Th-228 alpha reference source $(\mathrm{A}=3.7 \mathrm{kBq}), \mathrm{Gd}-148$ alpha particle standard $(\mathrm{A}=3.7 \mathrm{kBq}), \mathrm{Pu}-238$ large area source (active area radius $=25 \mathrm{~mm}, \mathrm{~A}=3.9 \mathrm{kBq}$ ) and $\mathrm{Am}-241$ large area source (active area radius $=25 \mathrm{~mm}, \mathrm{~A}=3.4 \mathrm{kBq}$ ). Due to its decay chain, Th-228 has seven energy maxima which are visible on the spectra. The reference date for all radionuclide activities is $06 / 24 / 2020$. All measurements with alpha sources were performed in a vacuum chamber at 1 mbar. 
Gamma irradiations were carried out at the Ruđer Bošković Institute's Secondary Standard Dosimetry Laboratory. We have used CIS Biointernational's radiotherapy calibration source of Co-60, $\mathrm{A}=14.5 \mathrm{TBq}, \mathrm{K}_{\mathrm{a}}=4.49 \mathrm{~Gy} / \mathrm{h}$ at source-to-surface distance (SSD) in a range from $1 \mathrm{~m}-5 \mathrm{~m}$. We have also used Hopewell Designs' radiation protection standard sources of Co-60, $\mathrm{A}=21.01 \mathrm{GBq}, \mathrm{K}_{\mathrm{a}}=6.78 \mathrm{mGy} / \mathrm{h}$ and Cs-137, $\mathrm{A}=505.87 \mathrm{GBq}, \mathrm{K}_{\mathrm{a}}=39.86 \mathrm{mGy} / \mathrm{h}$. The source of Cs-137 was used with additional attenuators with attenuating factors of 10,100 and 1000. The air kerma rates at SSD $=1 \mathrm{~m}$ were $4.49 \mathrm{~Gy} / \mathrm{h}, 383.11 \mu \mathrm{Gy} / \mathrm{h}$ and $48.61 \mu \mathrm{Gy} / \mathrm{h}$ respectively. Reference date for all gamma activities is 09/04/2020.

The electronic system used for measurements of signals induced in 4H-SiC SBDs consisted of a charge sensitive preamplifier (CREMAT CR-110, Cremat Inc, Newton, MA, USA), a Gaussian shaping amplifier (CREMAT CR-200-1 $\mu$ s), a multichannel analyzer (AMPTEK MCA 8000D, Amptek Inc, Bedford, MA, USA) and a laptop. Electrical power to the system was provided by a standalone battery-powered power supply in order to minimize the level of electronic noise. The reverse bias was applied to SBDs using a high voltage DC to DC converter (XP Power CA05P-5, XP Power, Singapore), also powered by the standalone power supply. The block diagram of the electronic system and its components is shown in Figure 3.

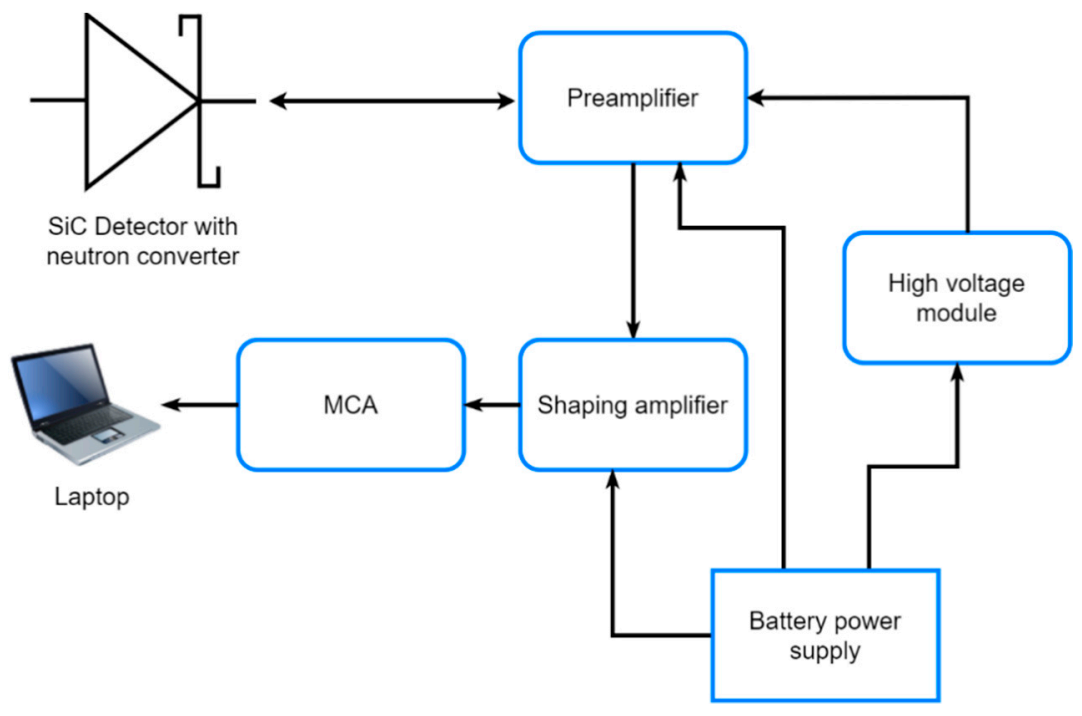

Figure 3. Block diagram of the detector system.

\section{Results}

The detector response was studied using alpha and gamma calibration sources. We have performed multiple irradiations of the detector prototype with various radiation sources in order to cover detection of a wide range of particle energy emissions. To observe both how irradiation affects the SBDs with a different active surface area, we performed thorough electrical characterization of SBDs before and after the irradiations.

\subsection{Electrical Characterization of SiC Detectors}

The quality of the prepared SBDs has been checked by I-V and C-V measurements, before and after the irradiation tests. All selected SBDs showed excellent rectifying characteristics. For clarity, we show here I-V (Figure 4a) and C-V (Figure 4b) characteristics for only one SBD before and after radiation tests. It should be noted that radiation tests did not introduce any changes to electrical or rectifying properties of used SBD's. Measurements of electrical characteristics of all three $4 \mathrm{H}-\mathrm{SiC}$ detectors are given in Supplementary files. The estimated $4 \mathrm{H}-\mathrm{SiC}$ detector's parameters are given in Table 1. 


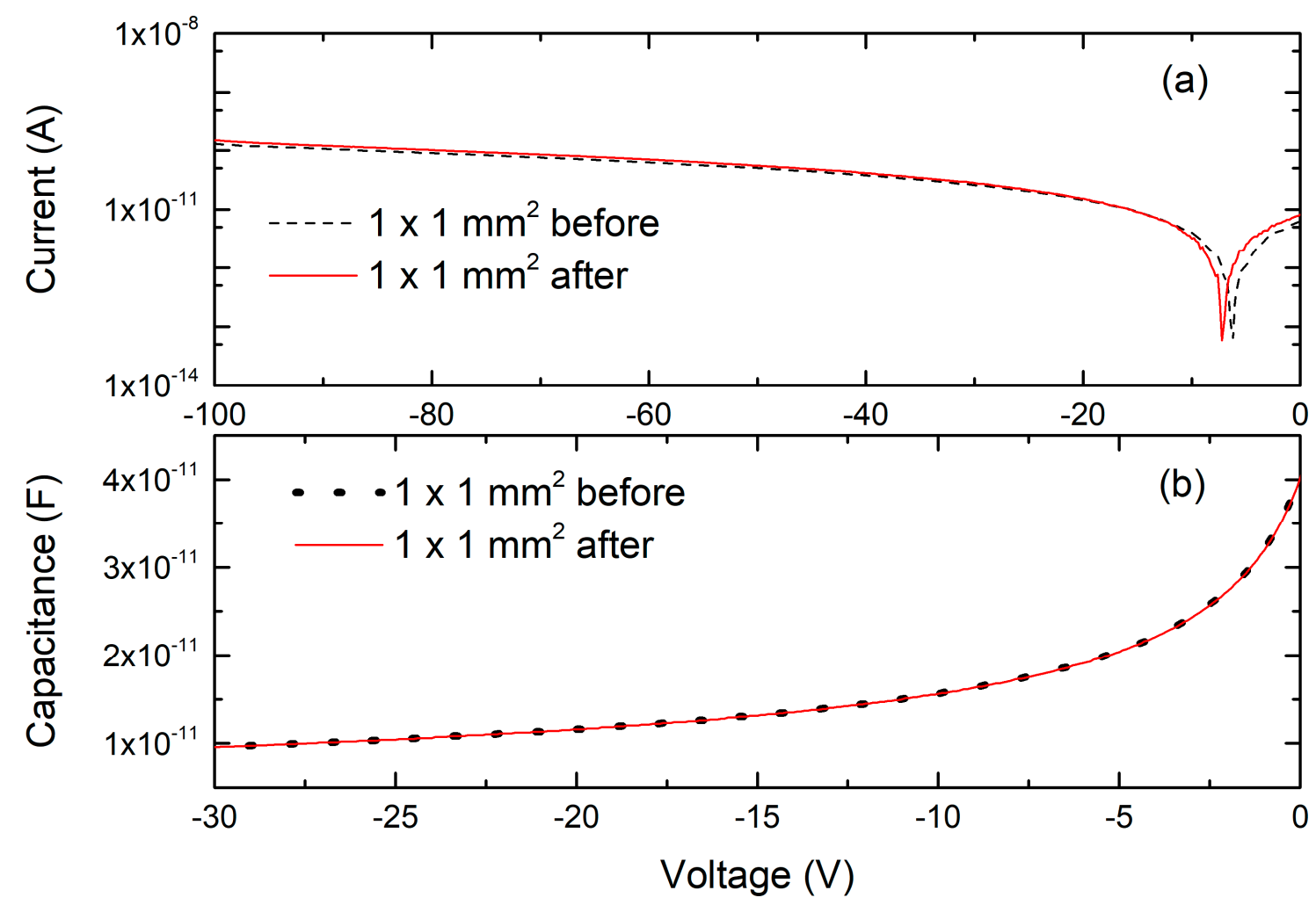

Figure 4. Measured electrical characteristics of $4 \mathrm{H}-\mathrm{SiC}$ detector with active surface area of $1 \times 1 \mathrm{~mm}^{2}$ before and after radiation testing at room temperature: (a) I-V characteristics and (b) C-V characteristics.

Table 1. SBD parameters before and after radiation testing.

\begin{tabular}{cccccc}
\hline \multicolumn{2}{c}{ Sample } & $\begin{array}{c}\text { Ideality } \\
\text { Factor }\end{array}$ & $\begin{array}{c}\text { Schottky Barrier } \\
\text { Height (eV) }\end{array}$ & Series Resistance $(\Omega)$ & Free Carrier Concentration (cm ${ }^{-3}$ ) \\
\hline \multirow{2}{*}{$1 \times 1 \mathrm{~mm}^{2}$} & Before & 1.010 & 1.61 & 45 & $4.4 \times 10^{14}$ \\
& After & 1.015 & 1.58 & 48 & $4.4 \times 10^{14}$ \\
\hline \multirow{2}{*}{$2 \times 2 \mathrm{~mm}^{2}$} & Before & 1.003 & 1.64 & 35 & $4.0 \times 10^{14}$ \\
& After & 1.080 & 1.55 & 65 & $4.2 \times 10^{14}$ \\
\hline \multirow{2}{*}{$3 \times 3 \mathrm{~mm}^{2}$} & Before & 1.017 & 1.60 & 28 & $4.7 \times 10^{14}$ \\
& After & 1.027 & 1.55 & 28 & $4.7 \times 10^{14}$ \\
\hline
\end{tabular}

Figure 5 shows DLTS spectra of the $4 \mathrm{H}-\mathrm{SiC}$ detector (a) before and (b) after the irradiation test. One prominent deep level defect, $Z_{1 / 2}$, is observed in both the pristine $4 \mathrm{H}-\mathrm{SiC}$ detector material and the irradiated detector material. The $\mathrm{Z}_{1 / 2}$ is a well-known deep level and previously assigned to a transition between double negative and neutral charge state of carbon vacancy $\mathrm{V}_{\mathrm{C}}(=/ 0)[26]$. As recently reported $[27,28]$, two emission lines, $Z_{1}(=/ 0)$ and $Z_{2}(=/ 0)$, are resolved by the Laplace DLTS technique and assigned to carbon vacancies residing on two different lattice sites with local cubic and hexagonal symmetry. Carbon vacancy is acting as a strong recombination center and is thus the main life-time limiting defect in as-grown $4 \mathrm{H}-\mathrm{SiC}$, which is one of the crucial properties for radiation detectors and electronic devices in general [29]. Radiation tests did not introduce any new deep level defects or increased the concentration of a carbon vacancy, which is a good indicator of radiation hardness of tested $4 \mathrm{H}-\mathrm{SiC}$ detectors. Determined activation energies and effective capture cross sections of electron emission for the observeddeep level $Z_{1 / 2}$ ) are given in Table 2. 


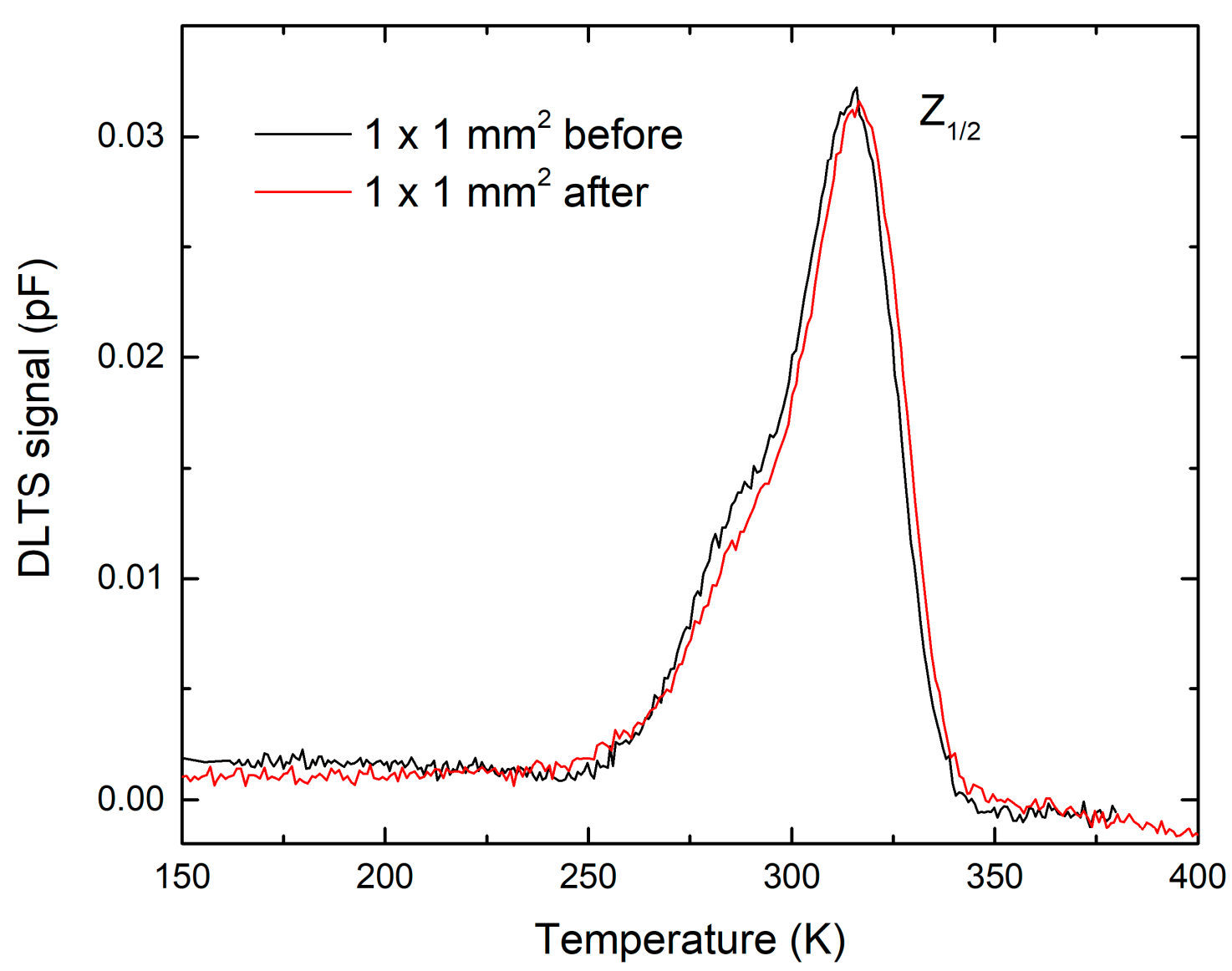

Figure 5. Shows a comparison of (a) DLTS spectra of the $4 \mathrm{H}-\mathrm{SiC}$ detector with active surface area of $1 \times 1 \mathrm{~mm}^{2}$ before and after radiation tests. Measurements settings were: reverse voltage $-10 \mathrm{~V}$, pulse bias $-0.1 \mathrm{~V}$, pulse width $10 \mathrm{~ms}$, and emission rate $50 \mathrm{~s}^{-1}$.

Table 2. $\mathrm{Z}_{1 / 2}$ deep level parameters obtained from DLTS spectra of $4 \mathrm{H}-\mathrm{SiC}$ detectors after radiation tests: activation energy, $E_{a}$, and effective carrier capture cross section, $\sigma_{a}$.

\begin{tabular}{ccc}
\hline Sample & $E_{a}(\mathrm{eV})$ & $\sigma_{a}\left(\mathrm{~cm}^{2}\right)$ \\
\hline $1 \times 1 \mathrm{~mm}^{2}$ & $0.68 \pm 0.01$ & $9 \times 10^{-15}$ \\
$2 \times 2 \mathrm{~mm}^{2}$ & $0.69 \pm 0.01$ & $1 \times 10^{-14}$ \\
$3 \times 3 \mathrm{~mm}^{2}$ & $0.67 \pm 0.01$ & $6 \times 10^{-15}$ \\
\hline
\end{tabular}

\subsection{Response of $4 \mathrm{H}$-SiC Detectors to Alpha Particles}

All irradiations of $4 \mathrm{H}-\mathrm{SiC}$ detectors with alpha particles having different energies were performed under low vacuum at $1 \mathrm{mbar}$, and a source-detector distance of $2 \mathrm{~mm}$. Table 3 shows an overview of all radionuclides used in this study with its emission energies and yield per decay. The Am-241 isotope is the most common alpha emitter used for testing of particle detectors. It is also widely used for calibrating/checking gamma spectrometry systems. Apart from the Am-241, we have used a wide range of alpha emitters including those rarely used for radiation testing, like Gd-148 and Th-228. 
Table 3. Overview of radionuclides used in this paper with their main emission energies and yield per decay [30].

\begin{tabular}{|c|c|c|c|}
\hline Radionuclide & $\begin{array}{c}\alpha \text { Emmision } \\
\text { Energy/ies with } \\
\text { Yield, (keV) }\end{array}$ & $\begin{array}{c}\beta \text { Emmision } \\
\text { Energy/ies with } \\
\text { Yield, (keV) }\end{array}$ & $\begin{array}{c}\gamma \text { Emmision } \\
\text { Energy/ies with } \\
\text { Yyield, (keV) }\end{array}$ \\
\hline Co-60 & - & $\begin{array}{l}318(100 \%), \\
1491(<1 \%)\end{array}$ & $\begin{array}{l}1173(100 \%) \\
1333(100 \%)\end{array}$ \\
\hline Cs-137 & - & $\begin{array}{l}512(95 \%) \\
1173(5 \%)\end{array}$ & $\begin{array}{c}662(85 \%) \\
32(6 \%)\end{array}$ \\
\hline Gd-148 & $3183(100 \%)$ & - & - \\
\hline Th-228 ${ }^{1}$ & $\begin{array}{c}5340,5423,5685,6050 \\
6288,6778 \text { and } 8784\end{array}$ & - & $84(1 \%)$ \\
\hline $\mathrm{Pu}-238$ & $\begin{array}{l}5499(71 \%) \\
5459(29 \%)\end{array}$ & - & $16(12 \%)$ \\
\hline $\mathrm{Pu}-239$ & $\begin{array}{l}5156(73 \%), \\
5143(15 \%), \\
5105(12 \%)\end{array}$ & - & $16(6 \%)$ \\
\hline Am-241 & $\begin{array}{l}5486(1 \%), \\
5443(13 \%), \\
5388(85 \%)\end{array}$ & - & $\begin{array}{l}60(36 \%), \\
18(18 \%), \\
14(13 \%)\end{array}$ \\
\hline $\mathrm{Cm}-244$ & $\begin{array}{l}5805(76 \%), \\
5763(24 \%),\end{array}$ & - & $17(11 \%)$ \\
\hline
\end{tabular}

\footnotetext{
${ }^{1}$ Th-228 has many energy maxima due to its radioactive decay chain (Th-228-Ra-224-Rn-220-Po-
} 216-Pb-212, Bi-212-Po-212-Pb-208).

Spectral response of detectors with an active area of $2 \times 2 \mathrm{~mm}^{2}$ to the mixed energy alpha particles is shown in Figure 6.
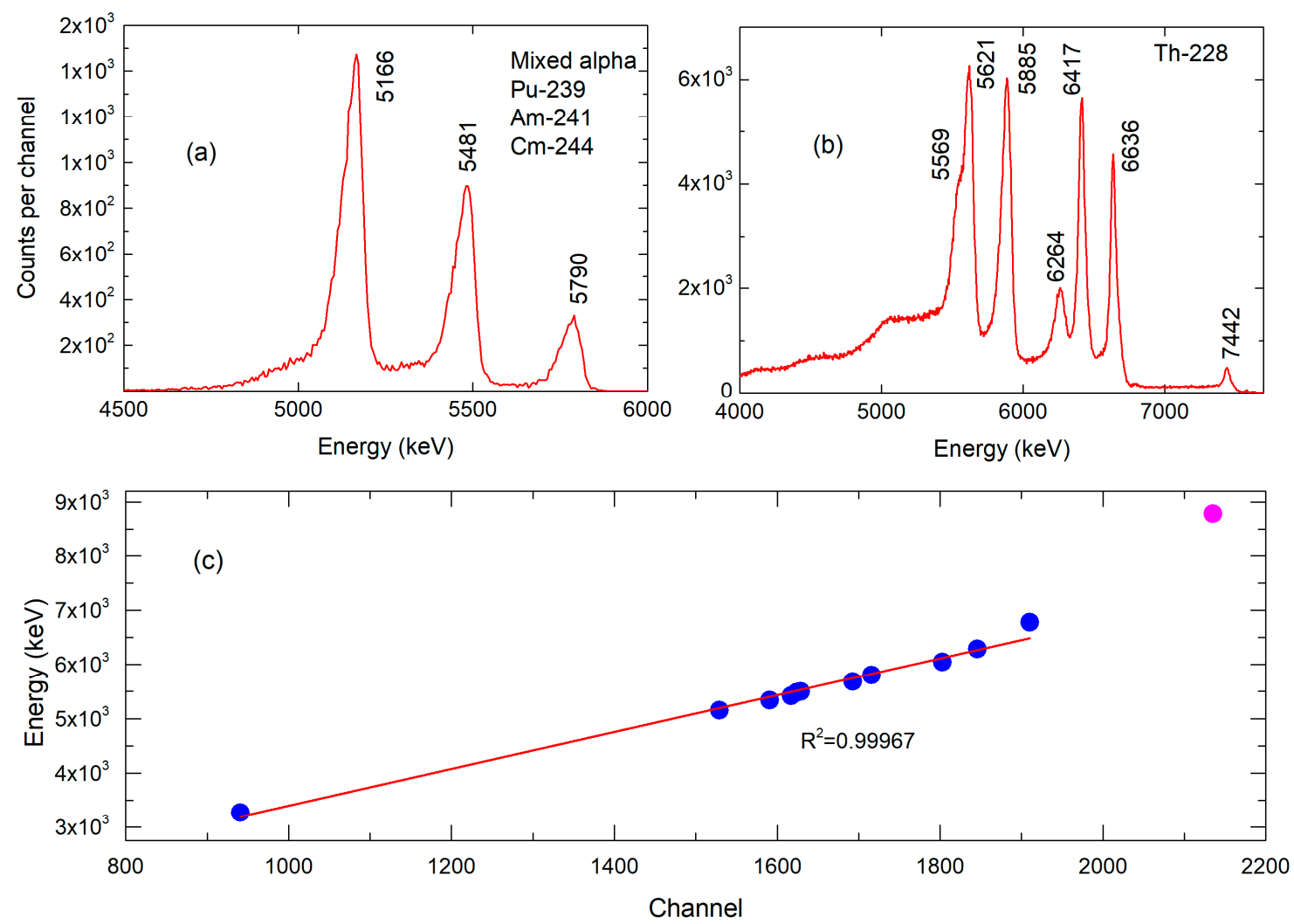

Figure 6. (a) Response of the $4 \mathrm{H}-\mathrm{SiC}$ detector with active surface area of $2 \times 2 \mathrm{~mm}^{2}$ to mixed alpha particle source (Pu-239, $\mathrm{Am}-241, \mathrm{Cm}-244)$ and (b) response of the same $4 \mathrm{H}-\mathrm{SiC}$ detector to Th-228 alpha reference source. (c) Linear regression analysis of the $4 \mathrm{H}-\mathrm{SiC}$ detector response over alpha decay energies of selected alpha particles, with active surface area of $2 \times 2 \mathrm{~mm}^{2}$. The following alpha particle sources were used: Gd-148 ( $\left.E_{\max }=3271 \mathrm{keV}\right)$, Th-228 ( $E_{\max }$ from its decay chain $=5340 \mathrm{keV}, 5423 \mathrm{keV}, 5685 \mathrm{keV}, 6050 \mathrm{keV}, 6288 \mathrm{keV}, 6778 \mathrm{keV}$ and $8784 \mathrm{keV}), \mathrm{Pu}-238\left(\mathrm{E}_{\max }=5499 \mathrm{keV}\right), \mathrm{Pu}-239$ $\left(E_{\max }=5157 \mathrm{keV}\right), \mathrm{Am}-241\left(\mathrm{E}_{\max }=5486 \mathrm{keV}\right)$, and $\mathrm{Cm}-244\left(\mathrm{E}_{\max }=5805 \mathrm{keV}\right)$. The $8784 \mathrm{keV}$ energy is presented here to show nonlinear response of the $4 \mathrm{H}-\mathrm{SiC}$ detector for the energies with a range in $\mathrm{SiC}$ higher than the epitaxial layer thickness. 
The detector shows a linear energy response for the energies below 6.7 MeV with the R-Square value of 0.99967 as shown in Figure 6c. All specified energies of alpha particles are detected/observed. Furthermore, recorded peak intensity ratios reproduce tabulated values for the alpha particles with the end of particle range within the epitaxial layer thickness. The spectral response of our detector to Th-228 and its daughter products is better than the response obtained by Jarrell et al. [31], where different energy maxima in correlation with epitaxial layer thickness was used for the determination of the thickness of an electrodeposited thorium film.

In order to get additional information regarding the detector response to alpha particle irradiation, we have increased the active surface area of our detector. Figure 7 shows the response of the three detectors with $1 \times 1 \mathrm{~mm}^{2}, 2 \times 2 \mathrm{~mm}^{2}$ and $3 \times 3 \mathrm{~mm}^{2}$ active area to the Am-241 alpha particle source. A large active area Am-241 source (diameter = $25 \mathrm{~mm}$ ) was used to measure the response of $4 \mathrm{H}-\mathrm{SiC}$ detectors with different active surface areas. A large area alpha source was used to minimize influence of the geometry to the response. Measurements were performed in vacuum for a time of $3600 \mathrm{~s}$. Acquired spectra by all $4 \mathrm{H}-\mathrm{SiC}$ detectors have characteristic Am-241 alpha decay peak at $5.486 \mathrm{MeV}$. Almost perfect linearity was established for alpha detection with different size detectors.

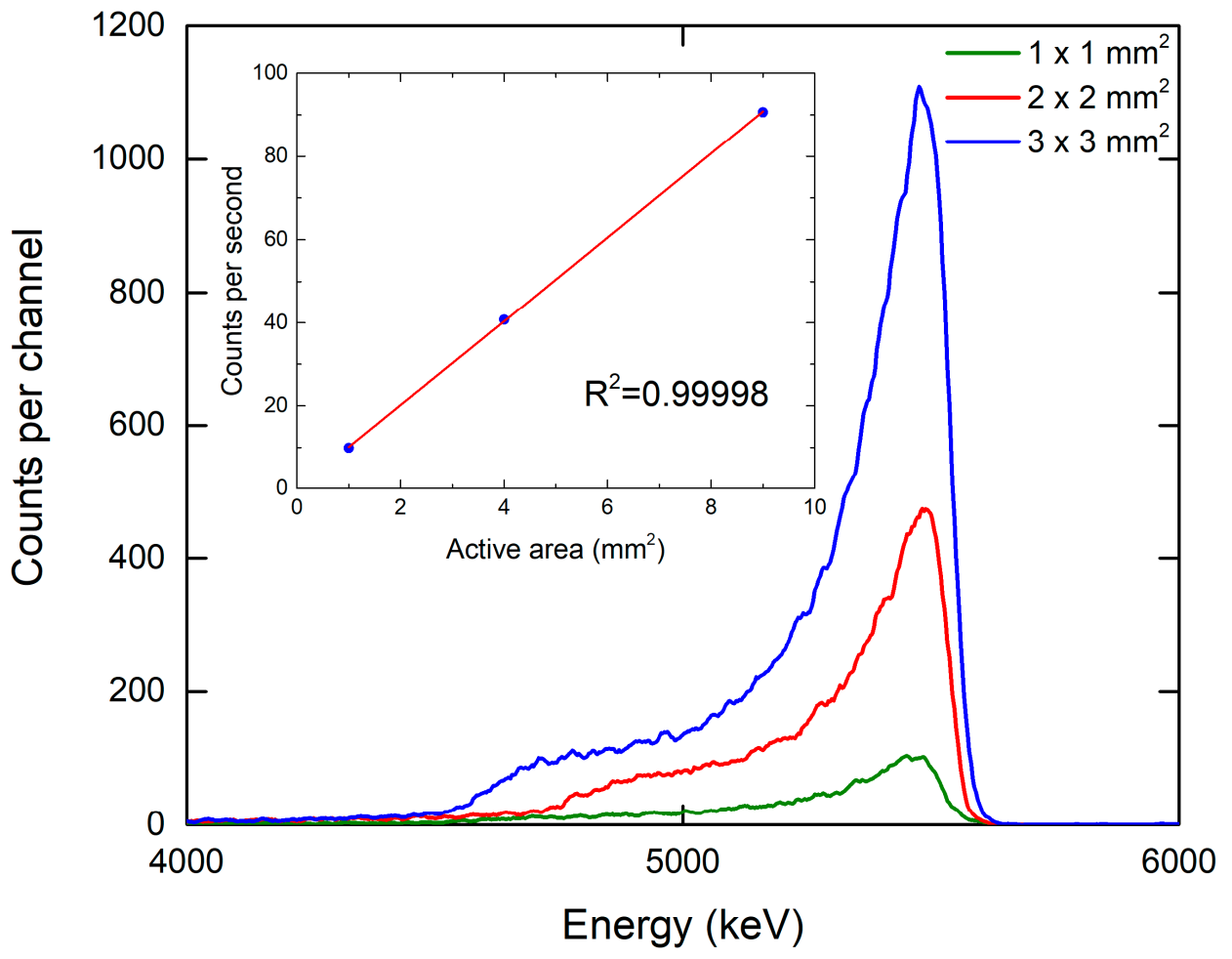

Figure 7. Response of $4 \mathrm{H}-\mathrm{SiC}$ detectors with different active surface areas $\left(1 \times 1 \mathrm{~mm}^{2}, 2 \times 2 \mathrm{~mm}^{2}\right.$ and $\left.3 \times 3 \mathrm{~mm}^{2}\right)$ to the Am-241 alpha particles with linear regression. We can observe excellent collation of $4 \mathrm{H}-\mathrm{SiC}$ detector response over the active detector area. There is no decrease in sensitivity of $4 \mathrm{H}-\mathrm{SiC}$ detectors by increasing its active area.

It is expected that further enlargement of active detector areas, higher than $3 \times 3 \mathrm{~mm}^{2}$, shall introduce a substantial amount of electronic noise and interferences.

All three detector sizes have an excellent spectral response for detection of various alpha emissions used in this work, except for the Po-212 alpha decay at $8785 \mathrm{keV}$ (in Th-228 radioactive chain). We have covered energies from $3183 \mathrm{keV}$ of Gd-148 to $6778 \mathrm{keV}$ of Po-216 (in Th-228 radioactive chain), therefore we have linear response of our $4 \mathrm{H}-\mathrm{SiC}$ detectors for the energies up to $6.8 \mathrm{MeV}$. The reason for the low efficiency of the $4 \mathrm{H}-\mathrm{SiC}$ detector to $8785 \mathrm{keV}$ alpha particles is the stopping power of the $25 \mu \mathrm{m} \mathrm{SiC}$ epitaxial layer. As simulated with SRIM (Stopping and Range of Ions in Matter [32,33]), $37.7 \mu \mathrm{m}$ is the 
range of $8.79 \mathrm{MeV}$ alpha particles in $\mathrm{SiC}$, and $24.6 \mu \mathrm{m}$ is the range of $6.7 \mathrm{MeV}$ alpha particles in $\mathrm{SiC}$.

Charge collection efficiency (CCE) of our fully depleted $4 \mathrm{H}-\mathrm{SiC}$ detectors for detection of alpha particles from the large area Am-241 source is up to $100 \%$. The best achieved energy resolution of our detector system, which was calculated from values of the full width at half maximum (FWHM), was 3\% for the Am-241 energy of $5486 \mathrm{keV}$ and 3.3\% for Gd-148 energy of $3183 \mathrm{keV}$. The obtained energy resolution is similar to previously published results $[11,17-19]$.

\subsection{Response of $4 \mathrm{H}-\mathrm{SiC}$ Detectors to Gamma Radiation}

We have obtained broad signal distribution in the low energy end of the spectra corresponding to partial deposited photon energy for ionization but above the electronic noise cut-off for all gamma irradiations performed in air, under monitored environmental conditions $\left(\mathrm{T}=18.3-19.4{ }^{\circ} \mathrm{C}, p=992.1-1001.7 \mathrm{hPa}\right)$. The epitaxial layer of $\mathrm{SiC}(25 \mu \mathrm{m})$ is not able to stop high-energy photons, therefore a well-defined spectral peak with Gaussian shape cannot be recorded in the photon energy spectrum.

We have noticed that irradiations of the $4 \mathrm{H}-\mathrm{SiC}$ detector with a higher air kerma rate results in fewer counts per air kerma than the irradiations of the $4 \mathrm{H}-\mathrm{SiC}$ detector with low air kerma rate. Slopes of the curves, intercept was fixed at 0 , were $12,860 \mathrm{mGy}^{-1}$ for Figure $8 \mathrm{a}, 11,007 \mathrm{mGy}^{-1}$ for Figure $8 \mathrm{~b}$ and $5004 \mathrm{mGy}^{-1}$ for Figure $8 \mathrm{c}$. Although the $4 \mathrm{H}-\mathrm{SiC}$ detector shows a linear response to dose while exposed to a high dose rate, as shown in Figure 8c, it should be mentioned that the $4 \mathrm{H}-\mathrm{SiC}$ detector is in saturation, which will be explained later. Linear response of the SiC detector to the air kerma was noticed before [14] but not the linear response to the dose rate as well. It is not possible to discriminate pulse-high signals from the $4 \mathrm{H}-\mathrm{SiC}$ detectors according to the gamma source energy. Although, Co-60 and Cs-137 sources are used mainly for gamma irradiations, they are also beta emitters. However, all gamma irradiations were performed through a thick PMMA layer so that beta particles could not reach the $4 \mathrm{H}-\mathrm{SiC}$ detector with the intensity that would have a significant impact on results. $\mathrm{SiC}$ could have potential to be used as a gamma radiation detector, but its low limit of detection would be quite high-above $0.5 \mathrm{mGy} / \mathrm{h}$.

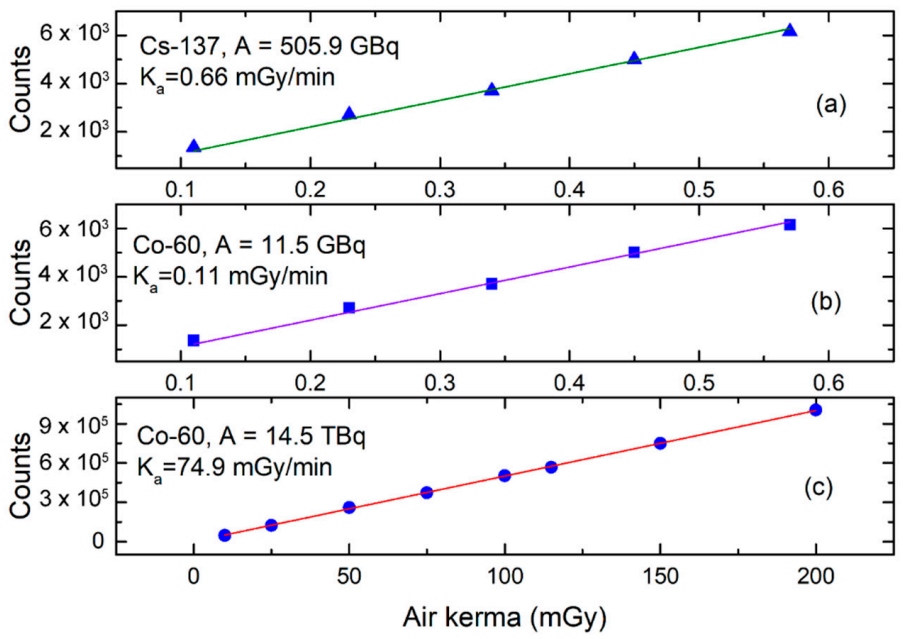

Figure 8. Response of $4 \mathrm{H}-\mathrm{SiC}$ detector with active surface area of $2 \times 2 \mathrm{~mm}^{2}$ to (a) Cs-137 source with activity of $505.9 \mathrm{GBq}$ and to two Co-60 sources with activities of $14.5 \mathrm{TBq}$ and $11.5 \mathrm{GBq}$, (b) and (c). Linear dose response of the $4 \mathrm{H}-\mathrm{SiC}$ detector is observed for a stronger and weaker $\mathrm{Co}-60$ source. However, different curve slopes suggest that the irradiations with lower air kerma rate results with creations of more electron-hole pairs per air kerma than the higher air kerma rate. The same behavior was observed for $4 \mathrm{H}-\mathrm{SiC}$ detectors with $1 \times 1 \mathrm{~mm}^{2}$ and $3 \times 3 \mathrm{~mm}^{2}$ surface area, but for clarity, only measurements with $2 \times 2 \mathrm{~mm}^{2} 4 \mathrm{H}-\mathrm{SiC}$ detector is presented here. 
We have made multiple irradiations of the $4 \mathrm{H}-\mathrm{SiC}$ detector with an active surface area of $2 \times 2 \mathrm{~mm}^{2}$ with the same air kerma while changing the air kerma rate, as shown in Figure 9. While exposed to dose rates of $15.29 \mathrm{mGy} / \mathrm{min}$ and lower, $4 \mathrm{H}-\mathrm{SiC}$ detector leaves the so-called saturation mode and is showing a constant count rate, which defines the upper limit of detection. Our detector system is limited, with a minimum input rise time of a multichannel analyzer (Section 2), therefore it cannot effectively detect pulses shorter than 500 ns. The delivered air kerma for all irradiations shown in Figure 9 was 50 mGy. For the same dose, response of the $4 \mathrm{H}-\mathrm{SiC}$ detector is not constant while in saturation. When the dose rate fell below $15.29 \mathrm{mGy} / \mathrm{min}$ (shaded in blue color in Figure 9), the $4 \mathrm{H}-\mathrm{SiC}$ detector's response was not related to the dose rate and remained a constant response rate with $\sigma= \pm 2.7 \%$.

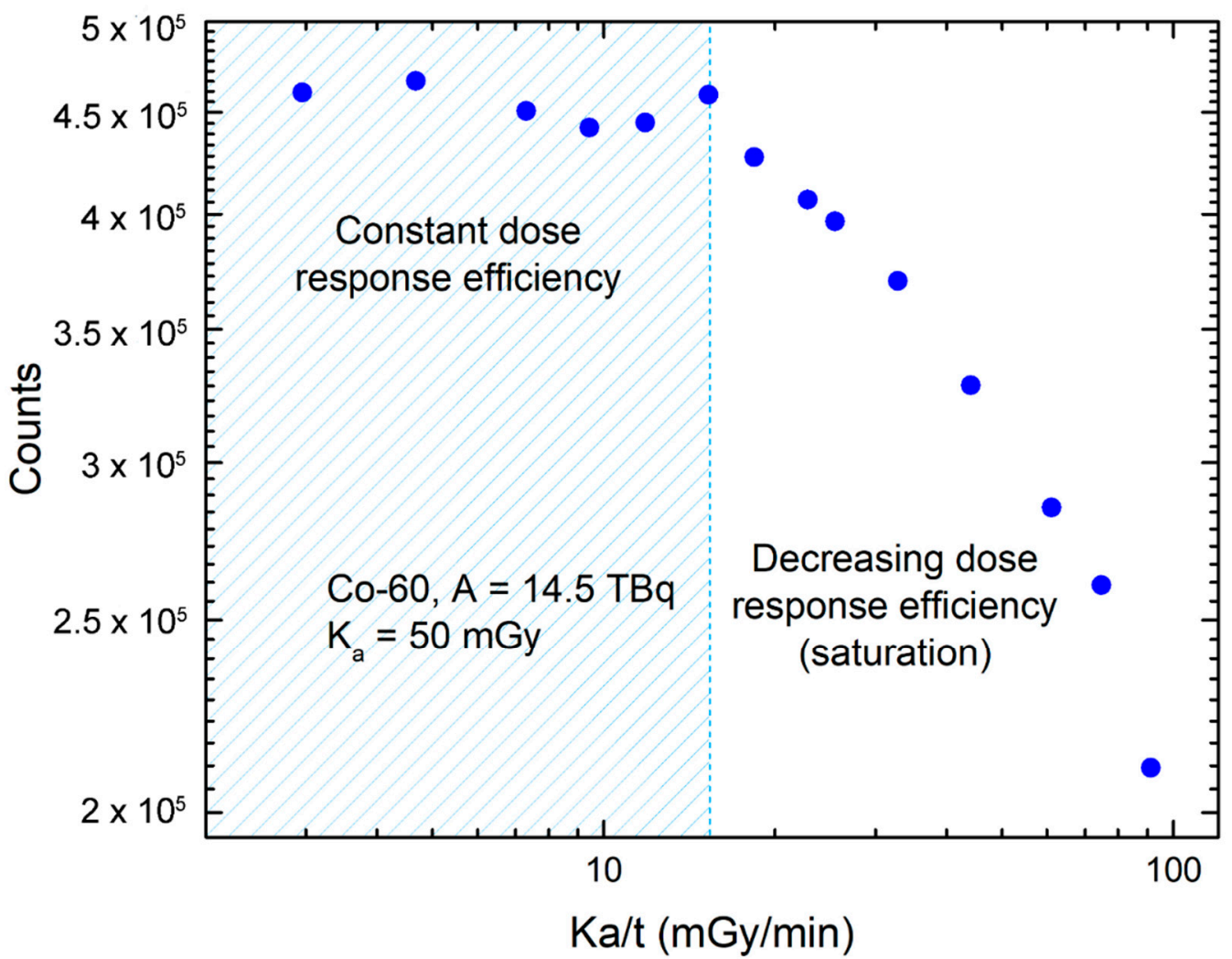

Figure 9. Response of $4 \mathrm{H}-\mathrm{SiC}$ detector with active surface area of $2 \times 2 \mathrm{~mm}^{2}$ to Co-60 source with activity of $14.5 \mathrm{TBq}$. Irradiations with were performed with different air kerma rates.

We have tested the response of the $4 \mathrm{H}-\mathrm{SiC}$ detector to a wide range of dose rates and the results show that the measuring range of $4 \mathrm{H}-\mathrm{SiC}$ detector for gamma radiation with energies of $662 \mathrm{keV}, 1.17 \mathrm{MeV}$ and $1.33 \mathrm{MeV}$ is from $0.5 \mathrm{mGy} / \mathrm{h}$ to $917 \mathrm{mGy} / \mathrm{h}$.

Figure 10 shows the response of three different $4 \mathrm{H}-\mathrm{SiC}$ detector sizes $\left(1 \times 1 \mathrm{~mm}^{2}, 2 \times\right.$ $2 \mathrm{~mm}^{2}$ and $3 \times 3 \mathrm{~mm}^{2}$ ) to gamma radiation. We can see that the gamma response over the size of the $4 \mathrm{H}-\mathrm{SiC}$ detector is good. However, the sensitivity of the $4 \mathrm{H}-\mathrm{SiC}$ detector with the largest active area is decreasing, which was not the case for the response of the SBD to alpha particles (Figure 7 ). We can see that the linear regression coefficient, $\mathrm{R}^{2}$, is lower than for the response of the $4 \mathrm{H}-\mathrm{SiC}$ detector to alpha particles. This is attributed to a difference in the amount of energy deposition in the active $4 \mathrm{H}-\mathrm{SiC}$ detector area for alpha and gamma radiation. Due to the thickness of epitaxial layer and gamma energy deposition, we have not observed good correlation of $4 \mathrm{H}-\mathrm{SiC}$ detector response with the active $4 \mathrm{H}-\mathrm{SiC}$ detector area. A possible solution could be a fabrication of $4 \mathrm{H}-\mathrm{SiC}$ detector with thicker epitaxial layer, as already implemented with high purity germanium detectors [3]. 


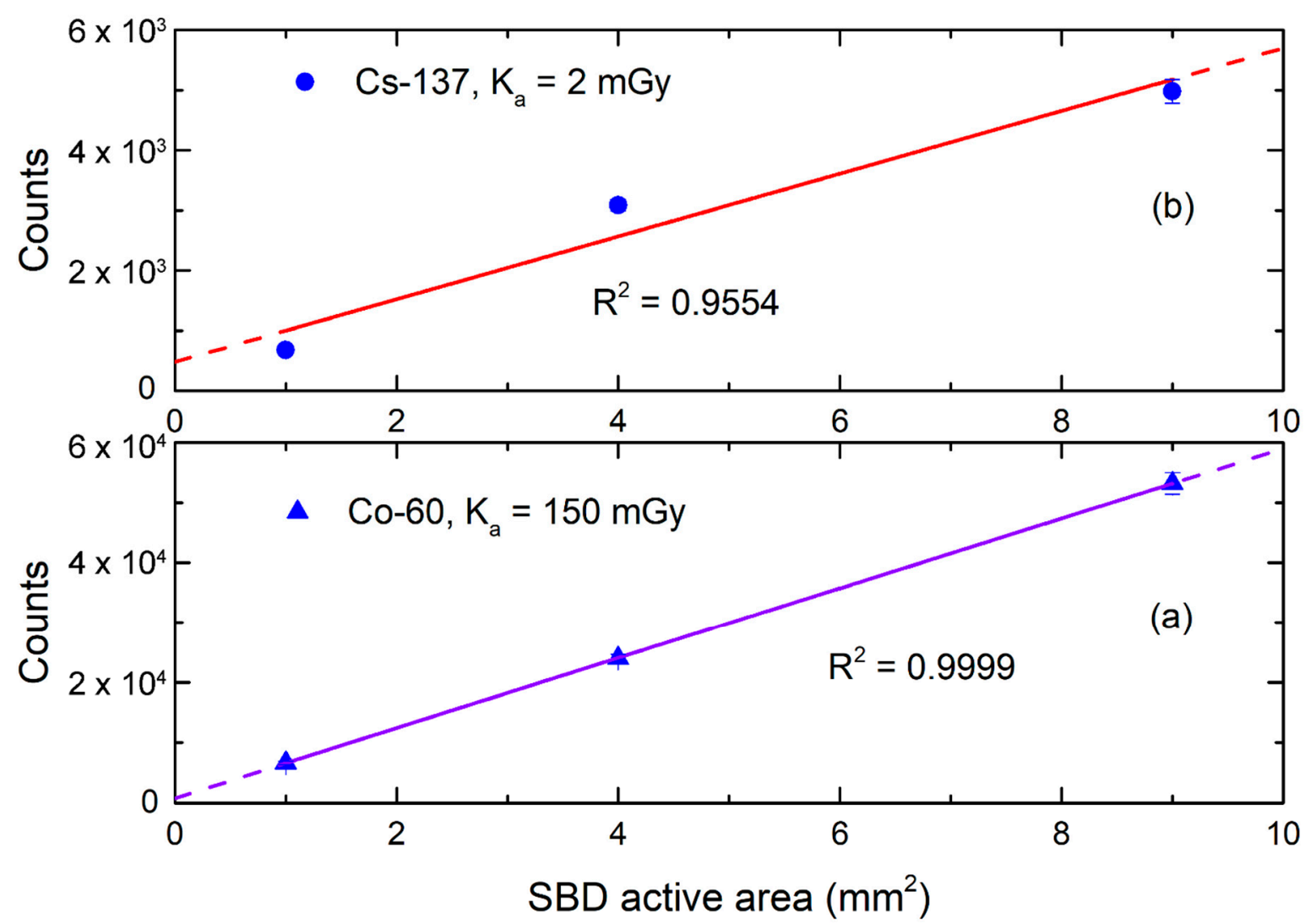

Figure 10. Response of three different $4 \mathrm{H}$-SiC detector sizes $\left(1 \times 1 \mathrm{~mm}^{2}, 2 \times 2 \mathrm{~mm}^{2}\right.$ and $3 \times 3 \mathrm{~mm}^{2}$ active surface area) to gamma sources of Cs-137 (a) and Co-60 (b). Solid line in showing linear fit for three $4 \mathrm{H}-\mathrm{SiC}$ detectors (active area of $1 \times$ $1 \mathrm{~mm}^{2}, 2 \times 2 \mathrm{~mm}^{2}$ and $\left.3 \times 3 \mathrm{~mm}^{2}\right)$.

Results shown in Figures 8-10 lead to a conclusion that the signal in the low energy end of the pulse height spectra cannot be attributed to the electronic noise or interference as the counting efficiency is dependent on delivered air kerma.

\section{Discussion}

Results of this study, combined with results of our tests published earlier, clearly demonstrate that the developed $4 \mathrm{H}-\mathrm{SiC}$ detector based on the SBD configuration is capable not only of detecting charged particles and neutrons (directly or indirectly via neutron converters), but to detect gamma radiation in a counting mode as well. Electric characteristics of the SBDs did not change over consecutive exposure to different radiation fields, which demonstrates the radiation hardness of used $4 \mathrm{H}-\mathrm{SiC}$ material. Free carrier concentration depth profiles did not change after the radiation testing. The $\mathrm{Z}_{1 / 2}$ deep level corresponding to carbon vacancy is the only observed defect in pristine and irradiated SiC material. Radiation tests with alpha and gamma sources have not introduced any changes in DLTS spectra.

The $4 \mathrm{H}-\mathrm{SiC}$ detector shows a linear energy response for the alpha particle energies below $6.7 \mathrm{MeV}$, the threshold energy that corresponds to the range of alpha particles approximately equal to the whole thickness of the $\mathrm{SiC}$ epitaxial layer. We did not observe substantial increase of electronic noise with increasing active surface area of the $4 \mathrm{H}-\mathrm{SiC}$ detector and the response is linear for all three different $4 \mathrm{H}-\mathrm{SiC}$ detector active areas, which means that there is no decrease in sensitivity of the $4 \mathrm{H}-\mathrm{SiC}$ detector with an increase in its active area. The best energy resolution of our detector system was 3\%, for the Am-241 energy of $5486 \mathrm{keV}$ and $3.3 \%$ for Gd-148 energy of $3183 \mathrm{keV}$.

Study of the $4 \mathrm{H}-\mathrm{SiC}$ detector response in gamma radiation field of Co- 60 and Cs-137 sources showed a linear response to air kerma and to different air kerma rates as well, up to 
$4.49 \mathrm{~Gy} / \mathrm{h}$. We have shown that the detector response is not in saturation for the dose rates lower than $15.3 \mathrm{mGy} / \mathrm{min}$ and that its measuring range for gamma radiation with energies of $662 \mathrm{keV}, 1.17 \mathrm{MeV}$, and $1.33 \mathrm{MeV}$ is from $0.5 \mathrm{mGy} / \mathrm{h}-917 \mathrm{mGy} / \mathrm{h}$. The gamma response over the active $4 \mathrm{H}-\mathrm{SiC}$ detector area is good. The linear regression coefficient $\mathrm{R}^{2}$, is lower than 0.999 , which is attributed to low CCE of the $4 \mathrm{H}-\mathrm{SiC}$ detectors to gamma radiation. The sensitivity of the detector with the largest active area is not in linear correlation with the other to $4 \mathrm{H}-\mathrm{SiC}$ detector active area sizes, and it decreases with the active area.

In summary, the obtained detector resolution of $3 \%$ for the wide alpha energy range combined with the linear response to gamma yield up to rates of $4.49 \mathrm{~Gy} / \mathrm{h}$ demonstrates the usability of this detector system for the detection of special nuclear materials through detection of thermal neutrons and gamma decays.

Supplementary Materials: The following are available online at https:/ / www.mdpi.com/2073-435 2/11/1/10/s1, Figure S1: Measured electrical characteristics of $4 \mathrm{H}-\mathrm{SiC}$ detector with active surface area of $2 \times 2 \mathrm{~mm}^{2}$ before and after radiation testing at room temperature (a) I-V characteristics and (b) C-V characteristics. Figure S2: Measured electrical characteristics of $4 \mathrm{H}-\mathrm{SiC}$ detector with active surface area of $2 \times 2 \mathrm{~mm}^{2}$ before and after radiation testing at room temperature (a) I-V characteristics and (b) $\mathrm{C}-\mathrm{V}$ characteristics.

Author Contributions: Formal analysis, R.B., L.B. and T.B.; investigation, R.B., I.C., L.B., T.B. and Ž.P.; resources, T.M., T.O. and A.S.; writing-original draft preparation, R.B., I.C. and L.B.; writingreview and editing, R.B., I.C., T.B., L.B., Ž.P., A.S., T.O. and T.M.; supervision, I.C. All authors have read and agreed to the published version of the manuscript.

Funding: This research was funded by NATO SPS Program, project number G5674. This research was partially funded by the National Collaborative Research Infrastructure Strategy (NCRIS) funding provided by the Australian Government. The RBI project team would like to acknowledge financial support from the European Regional Development Fund for the "Center of Excellence for Advanced Materials and Sensing Devices" (Grant No. KK.01.1.1.01.0001), “European Union's Horizon 2020 Research and Innovation Programme, grant number 669014", "European Union through the European Regional Development Fund-The Competitiveness and Cohesion Operational Programme, grant number KK.01.1.06".

Data Availability Statement: Data is contained within the article or supplementary materials.

Acknowledgments: We would like to acknowledge Hidekazu Tsuchida and Norihiro Hoshino Central Research Institute of Electric Power Industry for the supply of SiC substrates with epitaxially grown $4 \mathrm{H}-\mathrm{SiC}$ single-crystal layers.

Conflicts of Interest: The authors declare no conflict of interest. The funders had no role in the design of the study; in the collection, analyses, or interpretation of the data; in the writing of the manuscript, or in the decision to publish the results.

\section{References}

1. Liu, L.Y.; Wang, L.; Jin, P.; Liu, J.L.; Zhang, X.P.; Chen, L.; Zhang, J.F.; Ouyang, X.P.; Liu, A.; Huang, R.H.; et al. The fabrication and characterization of $\mathrm{Ni} / 4 \mathrm{H}-\mathrm{SiC}$ schottky diode radiation detectors with a sensitive area of up to $4 \mathrm{~cm}^{2}$. Sensors $2017,17,2334$. [CrossRef] [PubMed]

2. Hedayati, R.; Lanni, L.; Rodriguez, S.; Malm, B.G.; Rusu, A.; Zetterling, C.M. A monolithic, $500{ }^{\circ} \mathrm{C}$ operational amplifier in 4H-SiC bipolar technology. IEEE Electron Device Lett. 2014, 35, 693-695. [CrossRef]

3. Knoll, G.F. Radiation Detection and Measurement, 4th ed.; Wiley: Hoboken, NJ, USA, 2010.

4. Nava, F.; Bertuccio, G.; Cavallini, A.; Vittone, E. Silicon carbide and its use as a radiation detector material. Meas. Sci. Technol. 2008, 19, 102001. [CrossRef]

5. Sellin, P.J.; Vaitkus, J. New materials for radiation hard semiconductor dectectors. Nucl. Instrum. Methods Phys. Res. Sect. A Accel. Spectrometers Detect. Assoc. Equip. 2006, 557, 479-489. [CrossRef]

6. Tudisco, S.; La Via, F.; Agodi, C.; Altana, C.; Borghi, G.; Boscardin, M.; Bussolino, G.; Calcagno, L.; Camarda, M.; Cappuzzello, F.; et al. Sicilia-silicon carbide detectors for intense luminosity investigations and applications. Sensors 2018, 18, 2289. [CrossRef] [PubMed]

7. Morales-Chávez, J.; Herrera-Celis, J.; Saldana-Ahuactzi, Z.; Reyes-Betanzo, C.; Gómez-Montaño, F.J.; Orduña-Díaz, A. Silicon and hydrogenated amorphous silicon carbide as biofunctional platforms for immunosensors. Surf. Interfaces 2020, 20, 100550. [CrossRef] 
8. Naderi, N.; Moghaddam, M. Ultra-sensitive UV sensors based on porous silicon carbide thin films on silicon substrate. Ceram. Int. 2020, 46, 13821-13826. [CrossRef]

9. Verdon, C.; Szwedek, O.; Allemand, A.; Jacques, S.; Le Petitcorps, Y.; David, P. High temperature oxidation of two- and three-dimensional hafnium carbide and silicon carbide coatings. J. Eur. Ceram. Soc. 2014, 34, 879-887. [CrossRef]

10. Nava, F.; Vanni, P.; Bruzzi, M.; Lagomarsino, S.; Sciortino, S.; Wagner, G.; Lanzieri, C. Minimum ionizing and alpha particles detectors based on epitaxial semiconductor silicon carbide. IEEE Trans. Nucl. Sci. 2004, 51, 238-244. [CrossRef]

11. Ruddy, F.H.; Seidel, J.G.; Chen, H.; Dulloo, A.R.; Ryu, S.H. High-resolution alpha-particle spectrometry using $4 \mathrm{H}$ silicon carbide semiconductor detectors. IEEE Trans. Nucl. Sci. 2006, 53, 1713-1718. [CrossRef]

12. Radulović, V.; Yamazaki, Y.; Pastuović, Ž.; Sarbutt, A.; Ambrožič, K.; Bernat, R.; Ereš, Z.; Coutinho, J.; Ohshima, T.; Capan, I.; et al. Silicon carbide neutron detector testing at the JSI TRIGA reactor for enhanced border and port security. Nucl. Instruments Methods Phys. Res. Sect. A Accel. Spectrometers Detect. Assoc. Equip. 2020, 972, 164122. [CrossRef]

13. Hodgson, M.; Lohstroh, A.; Sellin, P.; Thomas, D. Characterization of silicon carbide and diamond detectors for neutron applications. Meas. Sci. Technol. 2017, 28, 105501. [CrossRef]

14. Pini, S.; Bruzzi, M.; Bucciolini, M.; Borchi, E.; Lagomarsino, S.; Menichelli, D.; Miglio, S.; Nava, F.; Sciortino, S. High-bandgap semiconductor dosimeters for radiotherapy applications. Nucl. Instrum. Methods Phys. Res. Sect. A Accel. Spectrom. Detect. Assoc. Equip. 2003, 514, 135-140. [CrossRef]

15. Moscatelli, F. Silicon carbide for UV, alpha, beta and X-ray detectors: Results and perspectives. Nucl. Instrum. Methods Phys. Res. Sect. A Accel. Spectrom. Detect. Assoc. Equip. 2007, 583, 157-161. [CrossRef]

16. Palestini, C. Advanced Technologies for Security Applications; Springer: Dordrecht, The Netherlands, 2019 ; ISBN 9789402420234.

17. Mandal, K.C.; Kleppinger, J.W.; Chaudhuri, S.K. Advances in high-resolution radiation detection using 4h-sic epitaxial layer devices. Micromachines 2020, 11, 254. [CrossRef]

18. Ruddy, F.H.; Dulloo, A.R.; Seidel, J.G.; Palmour, J.W.; Singh, R. The charged particle response of silicon carbide semiconductor radiation detectors. Nucl. Instrum. Methods Phys. Res. Sect. A Accel. Spectrom. Detect. Assoc. Equip. 2003, 505, 159-162. [CrossRef]

19. Ivanov, A.M.; Kalinina, E.V.; Kholuyanov, G.; Strokan, N.B.; Onushkin, G.; Konstantinov, A.O.; Hallén, A.; Kuznetsov, A.Y. High Energy Resolution Detectors Based on 4H-SiC. Mater. Sci. Forum 2005, 483-485, 1029-1032. [CrossRef]

20. Coutinho, J.; Torres, V.J.B.; Capan, I.; Brodar, T.; Ereš, Z.; Bernat, R.; Radulović, V. Silicon carbide diodes for neutron detection. Nucl. Inst. Methods Phys. Res. A 2020, 986, 164793. [CrossRef]

21. Flammang, R.W.; Seidel, J.G.; Ruddy, F.H. Fast neutron detection with silicon carbide semiconductor radiation detectors. Nucl. Instrum. Methods Phys. Res. Sect. A Accel. Spectrom. Detect. Assoc. Equip. 2007, 579, 177-179. [CrossRef]

22. Lioliou, G.; Chan, H.K.; Gohil, T.; Vassilevski, K.V.; Wright, N.G.; Horsfall, A.B.; Barnett, A.M. 4H-SiC Schottky diode arrays for X-ray detection. Nucl. Instrum. Methods Phys. Res. Sect. A Accel. Spectrom. Detect. Assoc. Equip. 2016, 840, 145-152. [CrossRef]

23. Ito, M.; Storasta, L.; Tsuchida, H. Development of $4 \mathrm{H}-\mathrm{SiC}$ epitaxial growth technique achieving high growth rate and large-area uniformity. Appl. Phys. Express 2008, 1, 2-5. [CrossRef]

24. Lang, D.V. Deep-level transient spectroscopy: A new method to characterize traps in semiconductors. J. Appl. Phys. 1974, 45, 3023-3032. [CrossRef]

25. Peaker, A.R.; Markevich, V.P.; Coutinho, J. Junction spectroscopy techniques and deep-level defects in semiconductors. J. Appl. Phys. 2018, 123, 161559. [CrossRef]

26. Son, N.T.; Trinh, X.T.; Løvlie, L.S.; Svensson, B.G.; Kawahara, K.; Suda, J.; Kimoto, T.; Umeda, T.; Isoya, J.; Makino, T.; et al. Negative-U system of carbon vacancy in 4H-SiC. Phys. Rev. Lett. 2012, 109, 23-27. [CrossRef] [PubMed]

27. Capan, I.; Brodar, T.; Pastuović, Z.; Siegele, R.; Ohshima, T.; Sato, S.I.; Makino, T.; Snoj, L.; Radulović, V.; Coutinho, J.; et al. Double negatively charged carbon vacancy at the h- and k-sites in 4H-SiC: Combined Laplace-DLTS and DFT study. J. Appl. Phys. 2018, 123, 161597. [CrossRef]

28. Capan, I.; Brodar, T.; Coutinho, J.; Ohshima, T.; Markevich, V.P.; Peaker, A.R. Acceptor levels of the carbon vacancy in 4H-SiC: Combining Laplace deep level transient spectroscopy with density functional modeling. J. Appl. Phys. 2018, $124,245701$. [CrossRef]

29. Booker, I.D.; Hassan, J.U.; Lilja, L.; Beyer, F.C.; Karhu, R.; Bergman, J.P.; Danielsson, Ö.; Kordina, O.; Sveinbjörnsson, E.Ö.; Janzén, E. Carrier lifetime controlling defects Z1/2 and RB1 in standard and chlorinated chemistry grown $4 \mathrm{H}-\mathrm{SiC}$. Cryst. Growth Des. 2014, 14, 4104-4110. [CrossRef]

30. Delacroix, D.; Guerre, J.P.; Leblanc, P.; Hickman, C.; Penney, B.C. Radionuclide and Radiation Protection Data Handbook. Med. Phys. 2003, 30, 277. [CrossRef]

31. Jarrell, J.; Stika, M.; Chaiken, M.; Simpson, M.; Blue, T.E.; Cao, L.R. Determination of the thickness of an electrodeposited thorium film with SiC alpha detectors. J. Radioanal. Nucl. Chem. 2017, 311, 1127-1133. [CrossRef]

32. Ziegler, J.F.; Ziegler, M.D.; Biersack, J.P. SRIM-The stopping and range of ions in matter. Nucl. Instrum. Methods Phys. Res. Sect. B Beam Interact. Mater. Atoms 2010, 268, 1818-1823. [CrossRef]

33. Ziegler, J.F.; Biersack, J.P. The Stopping and Range of Ions in Matter. In Treatise Heavy-Ion Science; Springer: Boston, MA, USA, 1985; pp. 93-129. 